\title{
The cerebrospinal fluid homovanillic acid concentration in patients with Parkinsonism treated with $\mathrm{L}$-dopa
}

\author{
G. CURZON, R. B. GODWIN-AUSTEN, E. B. TOMLINSON, AND \\ B. D. KANTAMANENI
}

From the Institute of Neurology, The National Hospital, Queen Square, London

\begin{abstract}
Almost all the dopamine in normal human brain is contained in the basal ganglia and related structures (Bertler, 1961). Very low dopamine concentrations are present in the caudate nucleus, putamen, and substantia nigra of subjects with Parkinson's disease (Ehringer and Hornykiewicz, 1960; Hornykiewicz, 1963; Bernheimer and Hornykiewicz, 1965). Lesions in the substantia nigra have been considered charateristic of Parkinsonism (Hassler, 1938; Greenfield and Bosanquet, 1953) and, therefore, the clinical significance of these biochemical observations is increased by the finding that stereotactic lesions in the substantia nigra of the rat or monkey cause depletion of dopamine in the caudate nucleus (Andén, Carlsson, Dahlström, Fuxe, Hillarp, and Larsson, 1964; Poirier and Sourkes, 1965). Dopamine does not readily cross the blood brain barrier, whereas its precursor dihydroxyphenylalanine (dopa) is able to do so, and has been reported to be effective in the treatment of patients suffering from Parkinsonism (Cotzias, Van Woert, and Schiffer, 1967; Yahr, Duvoisin, Hoehn, Schear, and Barrett, 1968; Cotzias, Papavasiliou, and Gellene, 1969; Calne, Stern, Laurence, Sharkey, and Armitage, 1969; GodwinAusten, Tomlinson, Frears, and Kok, 1969). It is probable, but as yet unproven, that this therapeutic response is the result of increased dopamine synthesis either in surviving striatal neurones or elsewhere in the brain.
\end{abstract}

In this investigation, the effect of L-dopa on Parkinson's disease and upon the cerebrospinal fluid (CSF) homovanillic acid (HVA) concentration is reported. HVA is a major dopamine metabolite and animal studies have shown that the HVA content of the cerebrospinal fluid correlates with brain dopamine turnover (Guldberg, 1969). The investigation of any correlation between HVA in the cerebrospinal fluid with severity of symptoms, associated brain damage, and therapeutic effectiveness of L-dopa should contribute to the under- standing of the mechanism of action of L-dopa in Parkinsonism.

\section{METHODS}

Nine patients were studied. They all had been resident in a long-stay hospital for between three months and seven years. They were selected from a population of 24 patients suffering from Parkinsonism and were accepted for treatment only if their agreement were given after details of the treatment and investigation had been explained. Patients were excluded from this trial if they showed significant physical disability unrelated to Parkinsonism.

Clinical assessment was carried out using a standard proforma of 57 items (Godwin-Austen et al., 1969). Symptoms and signs were assessed separately using a scoring system $0-$ normal, 3 - severe. Timed tests of walking, 'peg board', writing, and repetitive movements of the arms and legs were also used and the standard test proforma was supplemented in individual cases with special tests appropriate to significant but unlisted disabilities. Clinical assessments were done on three occasions. After the first and the second assessments $8 \mathrm{ml}$. of CSF was collected by lumbar puncture. Between the first and the second assessments all the patients were given $\mathrm{L}$-dopa in increasing dosage starting with $1.0 \mathrm{~g}$ daily and rising in increments of $1.0 \mathrm{~g}$ every two days to a maximum of $8 \mathbf{g}$ daily, divided into two doses, or until intolerance occurred. The patients were then continued on the maximum tolerated dose for three weeks before the second assessment and lumbar puncture was done. No alterations were made to the patients' previous drug therapy except in one patient where chlorpromazine was withdrawn before starting the trial, since phenothiazines may increase HVA levels (Da Prada and Pletscher, 1966). The dose of L-dopa was reduced when side-effects occurred but no additional therapy was prescribed for any side-effects. Aspirin was withheld as it interferes with the determination of HVA (Olsson and Roos, 1968). The second lumbar puncture was carried out between four and five-and-a-half hours after the morning dose of L-dopa. The L-dopa was then abruptly replaced by lactose placebo in identical capsules and 
dosage without the patients' knowledge. The final assessment was carried out three weeks later by an observer who knew that the patients were on placebo. Normal activities were continued throughout the period of the trial.

DETERMINATION OF HVA HVA was determined by a slightly modified combination of the methods of Andén, Roos, and Werdinius (1963) and of Murphy, Robinson, and Sharman (1969). Protein was precipitated from $8 \mathrm{ml}$. CSF by adding $2 \mathrm{ml}$. of $10 \%$ zinc sulphate followed by $1.2 \mathrm{ml}$. approximately $\mathrm{N}$ sodium hydroxide (strength adjusted so that final $p \mathrm{H}$ was just alkaline to phenolphthalein). After standing for a few minutes and centrifugation, $6 \mathrm{ml}$. supernatant was pipetted into a glassstoppered tube containing $25 \mathrm{ml}$. chloroform and shaken 100 times by hand. The phases were separated by centrifugation and $5 \mathrm{ml}$. of the aqueous phase taken, made to $p \mathrm{H} 2$ with $5 \mathrm{~N}$ hydrochloric acid, saturated with sodium chloride, and shaken mechanically for 15 minutes with $10 \mathrm{ml}$. butyl acetate (previously distilled and washed with $0.01 \mathrm{~N}$ hydrochloric acid and saturated with sodium chloride). After centrifugation, $8 \mathrm{ml}$. of the organic phase was taken in a conical centrifuge tube and back extracted into $1.5 \mathrm{ml} . p \mathrm{H} 7.40 .1 \mathrm{~N}$ sodium phosphate buffer by shaking mechanically for 15 minutes. After centrifugation, two $0.5 \mathrm{ml}$. portions of the aqueous phase were pipetted into test tubes. To one tube $0.5 \mathrm{ml}$. ferricyanide reagent was added (prepared immediately before use by adding $0.1 \mathrm{ml}$. of $2 \mathrm{mg} / \mathrm{ml}$. potassium ferricyanide to $10 \mathrm{ml}$. of 9N ammonium hydroxide). Exactly four minutes later $0.1 \mathrm{ml} .0 .1 \%$ cysteine (prepared immediately before required) was added and fluorescence read within one hour in a microcell on a Farrand spectrophotofluorometer (activation $=320 \mu$, fluorescence $=450 \mu$, Corning 7-54 and 3-73 filters in incident and emergent beams respectively, $20 \mathrm{~mm}$ slits). The second $0.5 \mathrm{ml}$. sample was used as a blank by adding the ferricyanide reagent after the cysteine. An HVA standard containing $100 \mu \mathrm{g} / \mathrm{ml}$. was stored in the deep freeze and $1 \mu \mathrm{g} / \mathrm{ml}$. working standards prepared fresh as required. One millilitre working standard $=7 \mathrm{ml}$. water was used instead of $8 \mathrm{ml}$. cerebrospinal fluid.

\section{RESULTS}

The results are summarized in Table 1. One patient (who is not included in the Table) developed spasmodic abnormal movements four days after starting

TABLE 1

CLINICAL ASSESSMENT AND HVA CONCENTRATION IN CSF BEFORE AND AFTER TREATMENT WITH L-DOPA ${ }^{1}$

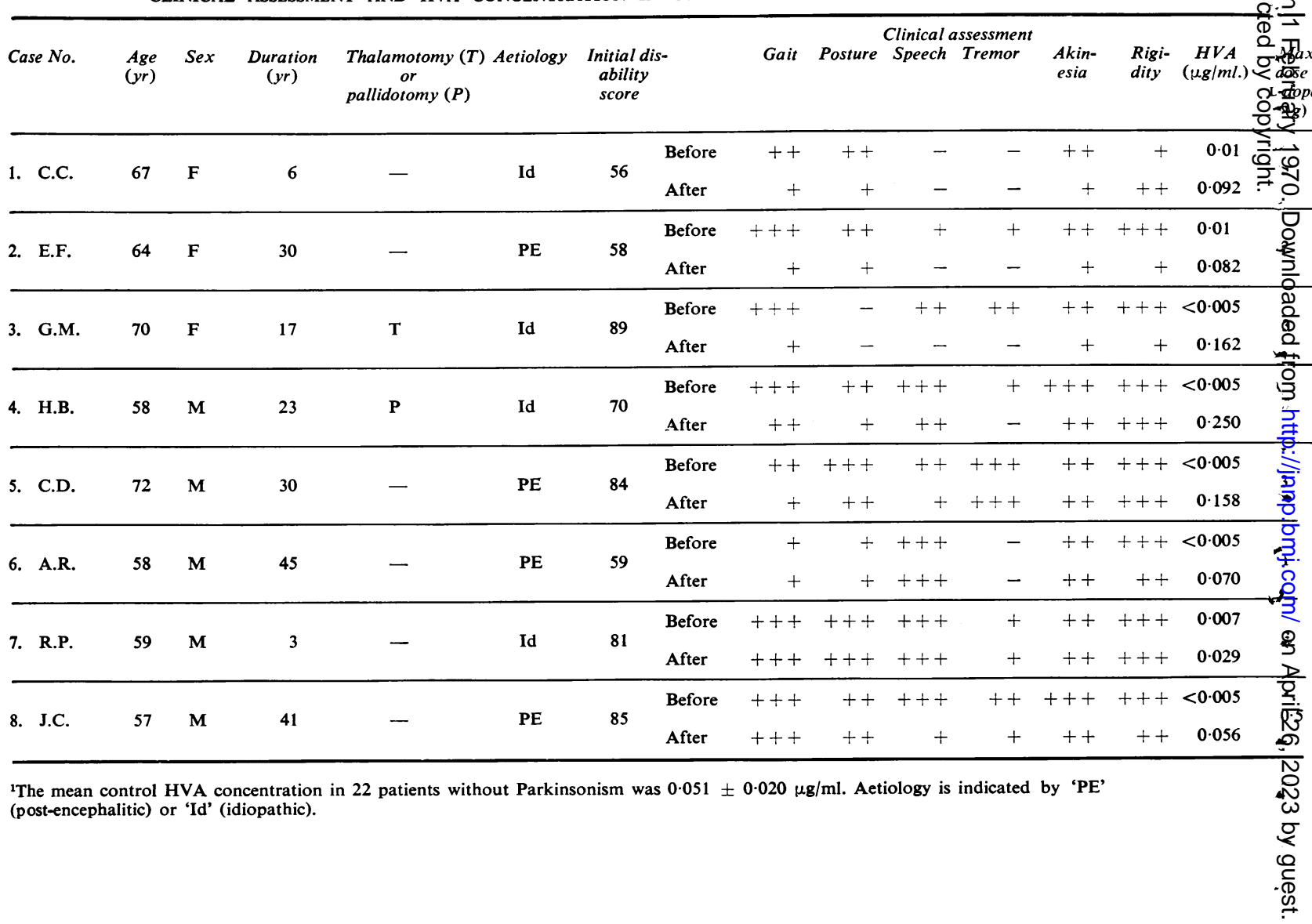


L-dopa at a dose of $\mathbf{2} \mathbf{g}$ daily and was withdrawn from the trial.

The patients are grouped according to their response to therapy. Three patients showed considerable benefit (cases 1, 2, and 3), two patients (cases 4 and 5) showed moderate or slight improvement and two patients showed no change in disability while taking L-dopa. One patient (case 8) developed a hyperactive confusional state necessitating withdrawal of L-dopa in spite of improvement in some features of his disability. $\mathrm{He}$ will be described separately.

The three patients who showed the greatest improvement were all female. Only one (case 2) had post-encephalitic Parkinsonism. The patients with the most severe disability and the least disability of all the patients investigated were in this group. Improvement was greatest in posture, walking, and independence with dressing and washing.

Case 1 was sufficiently improved in both posture and walking to render her wheelchair no longer necessary. Likewise, case 3, who had not walked for four years, despite surgical correction of a dystonic foot deformity five months previously, was able to walk unassisted about the ward after treatment with L-dopa. Two of these patients had tremor as part of their disability and both showed some improvement of their tremor. In one patient (case 3) this improvement was considerable as illustrated by her handwriting (Fig. 1). On objective assessment, rigidity and akinesia showed improvement in cases 1,2 , and 3.

\section{Before L-Dopa}

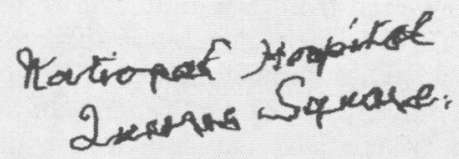

After L-Dopa

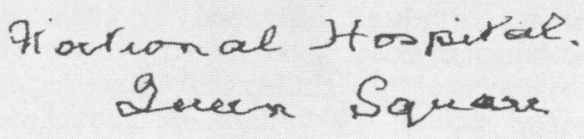

FIG. 1. Samples of handwriting from case 3 before and after taking L-dopa.

Two patients showed only moderate or slight benefit from treatment with $\mathrm{L}$-dopa. Case 4 was so dysarthric that assessment of subjective disability before treatment was greatly restricted. On L-dopa his speech became comprehensible and detailed assessment of his symptoms was possible. He became able to get out of a chair or bed without assistance and dress himself. This patient showed moderate intellectual impairment which was constant throughout the trial. Case 5 was a moderately disabled case of post-encephalitic Parkinsonism who improved in performance of such tasks as washing, shaving, writing and dressing, but objective assessment of tremor, rigidity and akinesia showed no improvement.

Two patients (cases 6 and 7) showed no improvement. One of these (case 6) had had encephalitis lethargica and his disability, which was of 45 years' duration, was less severe than case 7 who had developed idiopathic Parkinsonism only three years previously.

One patient (case 8), the youngest patient in this trial, was severely disabled from post-encephalitic Parkinsonism. He was chairbound with severe blepharospasm and required full nursing care. His speech was so soft as to be almost inaudible and voluntary movements were slow in initiation and execution. L-Dopa at a daily dose between 1 and $2 \mathrm{~g}$ produced relief of blepharospasm, and improvement in phonation so that he could be heard at a distance of $15 \mathrm{ft}$. There was also some improvement of bradykinesia, but at a dosage above $2 \mathrm{~g}$ daily he became restless and confused. Withdrawal of L-dopa was followed within 48 hours by the return of blepharospasm and dysphonia, but the confusional state resolved more slowly and some persisting mental changes were noted. Thus he required more nursing attention and was more intolerant. There was evidence of a confusional state in this patient at a dose of only $0.5 \mathrm{~g}$ daily, which was insufficient to produce useful therapeutic effect. The second lumbar puncture was done while he was taking only $0.5 \mathrm{~g}$ L-dopa daily. Although benefit was apparent at this time, it may have been a residual effect of the previous higher dose. Therefore, correlation between dosage, CSF findings, and clinical assessment was unreliable.

When placebo was substituted for L-dopa there was a gradual relapse in the clinical state in all the patients. At the time of the final assessment three weeks after withdrawing L-dopa four patients (cases 1, 2, 3, and 4) showed slight residual benefit from treatment, mainly noticeable as improvement in walking but also with tasks such as washing or writing.

In this small series of patients no clinical feature distinguished those patients who were likely to respond well to treatment with L-dopa. Three of the five patients who showed some benefit were female, whereas all the patients who showed no response were male. The average age of the patients who benefited was 66 years, whereas the patients who did not improve had an average age of 58 years. The 
average dosage of L-dopa tolerated by patients with post-encephalitic Parkinsonism was $1.6 \mathrm{~g}$ daily. Patients with idiopathic Parkinsonism tolerated a higher daily dose (average $4 \mathrm{~g}$ daily) without developing toxic side effects. This confirms the observations of Calne et al. (1969). Severity of initial disability did not correlate with therapeutic response.Thus the patient who showed the greatest disability (case 3) and the least disability (case 1) both derived considerable benefit from treatment. Likewise associated neurological deficit was no indication in this series of likely response. Thus case 4 who had had a pallidotomy showed moderate improvement in spite of intellectual impairment.

Two patients (cases 2 and 6) suffered oculogyric crises. In case 6 these were frequent both before and during therapy. Case 2 suffered oculogyric crises infrequently but had one while on L-dopa. These patients, therefore, differed from those of Calne et al. (1969) in whose patients oculogyric crises were abolished by L-dopa.

Cerebrospinal fluid HVA concentrations are also given in Table 1. HVA was undetectable (less than $0.005 \mu \mathrm{g} / \mathrm{ml}$.) in five patients before treatment with L-dopa. The two patients with the highest concentration of HVA before L-dopa (cases 1 and 2) were comparatively mildly disabled. After treatment with L-dopa, the HVA rose in all patients and correlated significantly with dose of L-dopa (Fig. 2). The greatest elevation was in case 4 from an undetectable level, to $0.25 \mu \mathrm{g} / \mathrm{ml}$. This patient tolerated $7 \mathrm{~g}$ L-dopa daily, which was also the highest dose tolerated by any patient in this series.

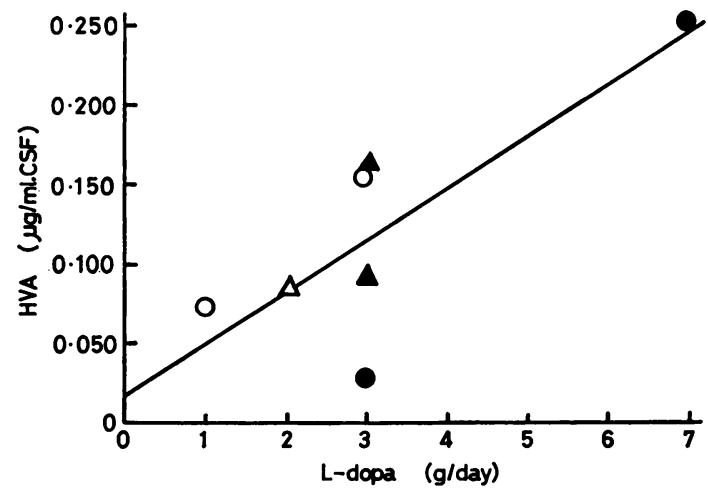

FIG. 2. Relationship between dose of L-dopa and HVA in cerebrospinal fluid. Dopa was given divided into two doses during the day. Lumbar CSF was taken four- to fiveand-a-half hours after the first dose. Subjects: male, idiopathic, 0 ; post-encephalitic, $O$; female, idiopathic, $\Delta$; post-encephalitic, $\Delta . y=0.03227 x+0.0170$. Correlation between $x$ and $y=0.798$ (significant at better than $5 \%$ level).
Cases 1 to 5 were benefited by treatment with L-dopa at an average daily dose of $3.6 \mathrm{~g}$. Their mean HVA concentration after treatment was $0.149 \mu \mathrm{g} / \mathrm{m}$. $\pm 0.067 \mu \mathrm{g} / \mathrm{ml}$., which may be compared with the lower HVA concentrations of cases 6 and $7(0.0 \%$ $\mu \mathrm{g} / \mathrm{ml}$. and $0.029 \mu \mathrm{g} / \mathrm{ml}$.) who showed little or $\mathrm{nog}$ improvement on 1 and $3 \mathrm{~g}$ daily respectively.

There was no correlation between post-treatme HVA in the four patients on the same dose of L-dopa and severity of disability or aetiology of the Parkinsonism. There was no overall correlation between the degree of improvement as assessed by our methods and HVA level. Furthermore, no correlation between the individual cardinal features of Parkinsonism and HVA could be shown. This lack of direct correlation is best exemplified by cases 3 and 5 who, despite different aetiologies, tolerated the same daily dose of $\mathrm{L}$-dopa $(3 \mathrm{~g})$ were of similar age, and in whom the initial disability was very similar. Their HVA concentrations after treatment were alsö similar but case 3 showed substantial clinical improves ment, whereas in case 5 benefit was only very slight

Two patients (cases 4 and 5) with relatively higets HVA levels after treatment showed slight or moderate improvement and two patients with low $\mathrm{H} \overline{\mathrm{Q}} \mathrm{A}$ levels (cases 6 and 7) showed no improvement. But the two patients in whom the greatest improvemint occurred (cases 1 and 2) had intermediate concentrations.

TOXIC EFFECTS Three patients (cases 3, 5, and experienced nausea and vomiting during the infos duction of $\mathrm{L}$-dopa. The nausea began about half-an $P$ hour after taking the capsules and continued for about four hours. In cases 3 and 5 the dose of L-dop had to be lowered from $5 \mathrm{~g}$ daily as a result of thi 궁 symptom. Three patients developed abnormal moveo ments. In two (cases 1 and 6) these consisted primaril of licking movements of the tongue and chewing movements of the jaw, but case 6 also develope athetoid movements of one hand. None of these patients appeared distressed by their abnormat movements. Case 3 developed repetitive kicking movements of the right leg with a frequency of about two per second. The duration of an attack was aboute 15 seconds. This patient had had two thalamotomies on the right side which resulted in some improvement in function of the left arm and leg.

Although case 8 underwent the most marked mental changes three other patients showed toxic mental changes. Thus case 1 became slightl $P$ aggressive and case 2 developed euphoria, whick was sufficiently severe to necessitate a reduction inf her dosage of dopa. Case 6 complained of feelings of tension and destructive impulses while takin dopa. 
Although hypotension has been previously reported as a toxic effect of L-dopa (Yahr etal., 1968; Calne et al., 1969; Godwin-Austen et al., 1969) none of these patients developed significant hypotension.

\section{DISCUSSION}

Treatment with L-dopa led to improvement in five out of nine patients, which is similar to experience in other trials (Calne et al., 1969; Godwin-Austen et al., 1969). The greatest improvement noted clinically was in the maintenance of a more normal posture and in speed of movement. Increased concentration in the CSF of the dopamine metabolite HVA invariably occurred, and there was a general positive correlation between L-dopa dosage and HVA concentration. There was no such clear relationship between dosage, HVA level attained, and degree of benefit. The interpretation of HVA changes might have been clarified if it were possible to determine their time course, but only a single specimen of CSF after L-dopa was taken as serial sampling of CSF is impractical.

The two patients with the lowest HVA after L-dopa treatment both showed no benefit. This is consistent with considerable dopamine synthesis in the brain being required for therapeutic effect. In one case this low level is easily explicable by the low dosage of L-dopa. The HVA level in the second patient, however, was markedly lower than that of other subjects on identical dosage. Whether this reflects particularly active peripheral L-dopa metabolism, slow transport to or metabolism in the brain, or rapid HVA clearance from the CSF cannot at present be determined. The lack of therapeutic and biochemical response to L-dopa in this patient was not associated with any unusual clinical features, except the short duration and rapid progression of his disease.

The five patients who improved on treatment had HVA levels of $0.082 \mu \mathrm{g} / \mathrm{ml}$. CSF or more. It is of interest that the patient (case 4) who tolerated the largest dose of L-dopa and whose HVA rose to the highest level recorded in this series only showed moderate improvement. Likewise case 5 showed relatively little benefit from L-dopa in spite of a relatively high HVA level, whereas cases 1 and 2 showed considerable improvement with HVA levels in the intermediate range. It may be relevant that case 4 had undergone pallidotomy and showed moderate intellectual impairment. Case 5, however, showed no intellectual impairment, had not had a thalamotomy and showed no evidence of neurological deficit outside the extra-pyramidal system. It is possible that a considerable fraction of HVA in 2 cases 4 and 5 was produced extra-striatally, because dopamine is formed from L-dopa by the action of decarboxylase, which is widely distributed in the brain (Kuntzman, Shore, Bogdanski, and Brodie, 1961). Normally only small amounts of dopamine are present in the brain except in the striatum (Bertler, 1961) presumably because of relatively rapid metabolism of dopamine formed elsewhere (Glowinski and Iversen, 1966). Exogenous L-dopa, however, may considerably increase extra-striatal as wellas striatal dopamine in the brain (Dagirmanjian, Laverty, Mantegazzini, Sharman, and Vogt, 1963; Bartholini and Pletscher, 1968).

The evidence presented here suggests that, although considerably increased brain dopamine synthesis (shown by increased HVA in the cerebrospinal fluid) appears to be necessary for L-dopa to be therapeutically effective, increased dopamine synthesis does not necessarily imply a therapeutic response. The therapeutic effectiveness of L-dopa treatment in Parkinsonism may not depend upon the net amount of brain dopamine formed from L-dopa but on the fraction of the dopamine formed or accumulating in the striatum. This in turn depends on surviving striatal dopaminergic nerve endings. Severely handicapped patients might be expected to have fewer striatal dopaminergic neurones and thus to respond less well to dopa than those patients who were less handicapped. No such relationship was apparent in this series but a recent clinical trial of L-dopa (Godwin-Austen et al., 1969) suggested that the most disabled patients showed least benefit from treatment.

Evidence whether therapeutic response to L-dopa is dependent upon striatal dopamine formation or accumulation will require post-mortem determination of the distribution of dopamine and HVA in brains of subjects with Parkinsonism treated with L-dopa and showing different degrees of benefit.

\section{SUMMARY}

The response of eight patients with Parkinsonism to treatment with L-dopa has been studied and correlated with changes in the homovanillic acid (HVA) concentration in the cerebrospinal fluid (CSF). Before treatment HVA concentration was low or undetectable in all patients and after treatment the HVA concentration rose to a level which correlated significantly with the dose of L-dopa. The lowest HVA levels after treatment were in the two patients who showed no benefit. One patient showed little therapeutic benefit but developed a relatively high HVA level. The two patients in whom clinical improvement was greatest had HVA levels intermediate between the patients who showed no response and 
those whose response was moderate or slight.

It is suggested that increased brain synthesis of dopamine as reflected by increased cerebrospinal fluid HVA levels is necessary for a therapeutic response to L-dopa but that increased brain dopamine synthesis does not necessarily lead to a therapeutic response.

The patients who underwent treatment in this investigation were all in-patients at the Royal Hospital and Home for Incurables, Putney. We wish to thank Dr. R. E. Kelly and Dr. V. Kendall for their help in organizing this investigation and Dr. D. F. Sharman for giving details of a method of dopamine determination before its publication. The Institute of Neurology provided research grants for Dr. E. B. Tomlinson and Mrs. B. D. Kantamaneni.

\section{REFERENCES}

Andén, N. E., Carlsson, A., Dahlström, A., Fuxe, K., Hillarp, N. A., and Larsson, K. (1964). Demonstration and mapping out of nigro-neostriatal dopamine neurons. Life Sci., 3, 523-530.

-, Roos, B. E., and Werdinius, B. (1963). On the occurrence of homovanillic acid in brain and cerebrospinal fluid and its determination by a fluorometric method. Ibid. 2, 448-458.

Bartholini, G., and Pletscher, A. (1968). Cerebral accumulation and metabolism of $\mathrm{C}^{14}$-dopa after selective inhibition of peripheral decarboxylase. J. Pharmacol. exp. Therap., 161, 14-20.

Bernheimer, H., and Hornykiewicz, O. (1965). Herabgesetzte Konzentration der Homovanillinsaüre im Gehirn von parkinsonkranken Menschen als Ausdruck der Störung des zentralen Dopaminstoffwechsels. Klin. Wschr., 43, 711-715.

Bertler, A. (1961). Occurrence and localization of catechol amines in the human brain. Acta physiol. Scand., 51, 97-107.

Calne, D. B., Stern, G. M., Laurence, D. R., Sharkey, J., and Armitage, P. (1969). L-dopa in postencephalitic Parkinsonism. Lancet, 1, 744-747.

Cotzias, G. C., Papavasiliou, P. S., and Gellene, R. (1969). Modifcation of Parkinsonism-Chronic treatment with L-dopa. New Engl. J. Med., 280, 337-345.

-, Van Woert, M. H., and Schiffer, L. M. (1967). Aromatic amino acids and modification of Parkinsonism. Ibid., 276, 374-379.
Dagirmanjian, R., Laverty, R., Mantegazzini, P., Sharman, D. F. and Vogt, M. (1963). Chemical and physiological change produced by arterial infusion of dihydroxyphenylalanine in $\mathbb{B}$ one cerebral hemisphere of the cat. J. Neurochem., 10, 177-18

Da Prada, M., and Pletscher, A. (1966). Acceleration of the cerebre) dopamine turnover by chlorpromazine. Experientia (Base $22,465$.

Ehringer, H., and Hornykiewicz, O. (1960). Verteilung von Norado renalin und Dopamin (3-Hydroxytyramin) im Gehirn degs Menschen und ihr Verhalten bei Erkrankungen des extres pyramidalen Systems. Klin. Wschr., 38, 1236-1239.

Glowinski, J., and Iversen, L. L. (1966). Regional studies of cat cholamines in the rat brain-1. The disposition of $\left[{ }^{3} \mathrm{H}\right]$ Nore pinephrine, $\left[{ }^{3} \mathrm{H}\right]$ Dopamine and $\left[{ }^{3} \mathrm{H}\right]$ Dopa in various regions of the brain. J. Neurochem., 13, 655-669.

Godwin-Austen, R. B., Tomlinson, E. B., Frears, C. C., and KoK H. W. L. (1969). Effects of L-dopa in Parkinson's disease Lancet, 2, 165-168.

Greenfield, J. G., and Bosanquet, F. D. (1953). The brain-stem lesion in Parkinsonism. J. Neurol. Neurosurg. Psychiat., 16, 213-226

Guldberg, H. C. (1969). Changes in amine metabolite concentrations in cerebrospinal fluid as an index of turnover. p. 55 in Meta bolism of Amines in the Brain. Edited by G. Hooper. Mass millan: London.

Hassler, R. (1938). Zur Normalanatomie der Substantia nigro Versuch einer architektonischen Gliederung. J. Psychof. Neurol. (Lpz.), 48, 1-55.

Hornykiewicz, O. (1963). Die topische Lokalisation und das Verhaltefu von Noradrenalin und Dopamin (3-Hydroxytyramin) in dê: Substantia nigra des normalen und Parkinson-krankē Menschen. Wien. klin. Wschr., 75, 309-312.

Kuntzman, R., Shore, P. A., Bogdanski, D., and Brodie, B. B. (1961 Microanalytical procedures for fluorometric assay of braie dopa-5HTP decarboxylase, norepinephrine and serotonin, an a detailed mapping of decarboxylase activity in brain Neurochem., 6, 226-232.

Murphy, G. F., Robinson, D., and Sharman, D. F. (1969). The efect of tropolone on the formation of 3,4-dihydroxyphenylaftic. acid and 4-hydroxy-3-methoxyphenylacetic acid in the brain of the mouse. Brit. J. Pharmacol., 36, 107-115.

Olsson, R., and Roos, B. E. (1968). Concentrations of 5-hydrok doleacetic acid and homovanillic acid in the cerebrospmat fluid after treatment with Probenecid in patients with Parging son's disease. Nature (Lond.), 219, 502-503.

Poirier, L. J., and Sourkes, T. L. (1965). Influence of the substaria nigra on the catecholamine content of the striatum. Brain 38 ?
181-192.

Yahr, M. D., Duvoisin, R. C., Hoehn, M. M., Schear, M. J., and Barrett, R. E. (1968). L-dopa (L-3,4-dihydroxyphenylalanine) its clinical effects in Parkinsonism. Trans. Amer. neurol. Ass 93, 56-63. 